\title{
Structure of the three-way helical junction of the hepatitis $C$ virus IRES element
}

\author{
JONATHAN OUELLET, SONYA MELCHER, ASIF IQBAL, YILIANG DING, ${ }^{1}$ and DAVID M.J. LILLEY \\ Cancer Research UK Nucleic Acid Structure Research Group, MSI/WTB Complex, The University of Dundee, Dundee DD1 5EH, \\ United Kingdom
}

\begin{abstract}
The hepatitis $C$ virus internal ribosome entry site (IRES) element contains a three-way junction that is important in the overall RNA conformation, and for its role in the internal initiation of translation. The junction also illustrates some important conformational principles in the folding of three-way helical junctions. It is formally a $3 \mathrm{HS}_{4}$ junction, with the possibility of two alternative stacking conformers. However, in principle, the junction can also undergo two steps of branch migration that would form $2 \mathrm{HS}_{1} \mathrm{HS}_{3}$ and $2 \mathrm{HS}_{2} \mathrm{HS}_{2}$ junctions. Comparative gel electrophoresis and ensemble fluorescence resonance energy transfer (FRET) studies show that the junction is induced to fold by the presence of $\mathbf{M g}^{2+}$ ions in low micromolar concentrations, and suggest that the structure adopted is based on coaxial stacking of the two helices that do not terminate in a hairpin loop (i.e., helix IIId). Single-molecule FRET studies confirm this conclusion, and indicate that there is no minor conformer present based on an alternative choice of helical stacking partners. Moreover, analysis of single-molecule FRET data at an 8-msec resolution failed to reveal evidence for structural transitions. It seems probable that this junction adopts a single conformation as a unique and stable fold.
\end{abstract}

Keywords: RNA structure; RNA junctions; translation; FRET; single-molecule fluorescence

\section{INTRODUCTION}

The internal ribosome entry site (IRES) of the hepatitis $\mathrm{C}$ virus (HCV) binds eIF3 and the small ribosomal subunit, allowing internal initiation of translation to occur independently of a capped 5' terminus (Tsukiyama-Kohara et al. 1992; Wang et al. 1993; Sizova et al. 1998). This 341nucleotide (nt) RNA is found upstream of a gene encoding a large polyprotein. The HCV IRES RNA is highly conserved, and adopts a folded structure in the presence of divalent metal ions (Kieft et al. 1999; Spahn et al. 2001). The RNA has a complex secondary structure (Brown et al. 1992; Reynolds et al. 1995; Rijnbrand et al. 1995; Honda et al. 1996), which includes a number of helical junctions, shown schematically in Figure 1A. Domain III includes a prominent four-way junction. Using the IUB nomenclature of helical junctions (Lilley et al. 1995), this junction is defined

\footnotetext{
${ }^{1}$ Present address: Department of Chemistry, Penn State University, University Park, PA 16802, USA.

Reprint requests to: David M.J. Lilley, Cancer Research UK Nucleic Acid Structure Research Group, MSI/WTB Complex, The University of Dundee, Dundee DD1 5EH, United Kingdom; e-mail: d.m.j.lilley@dundee. ac.uk; fax: +44-1382-345893.

Article published online ahead of print. Article and publication date are at http://www.rnajournal.org/cgi/doi/10.1261/rna.2158410.
}

as $2 \mathrm{HS}_{2} 2 \mathrm{HS}_{1}$, indicating the number of helical $(\mathrm{H})$ and linking segments (S) sequentially around the branchpoint. There is also a less well-defined junction involving helices IIIe and IIIf, and a three-way junction that includes helix IIId (Fig. 1B). Elements of the structure have been determined (Klinck et al. 2000; Lukavsky et al. 2000; Kieft et al. 2002; Lukavsky et al. 2003). We have previously studied the structure and dynamic properties of the $2 \mathrm{HS}_{2} 2 \mathrm{HS}_{1}$ four-way junction. The structure of a related construct was solved by X-ray crystallography (Kieft et al. 2002), but we found that this junction was either a stacked cross with axes perpendicular or a dynamic structure oscillating between parallel and anti-parallel stacked structures (Melcher et al. 2003). Interestingly, an anti-parallel conformation was suggested by a single-particle cryo-electron microscopy (cryo-EM) study (Boehringer et al. 2005), whereas a parallel conformation was found in the crystal structure (Kieft et al. 2002).

The three-way junction has not been the subject of extensive study, either structurally or functionally. The structure of helix IIId has been studied by nuclear magnetic resonance (NMR) (Klinck et al. 2000; Lukavsky et al. 2000), and the effects of mutations within this helix on IRES activity have been analyzed. To date, there has been no study of the effects of mutations within the core of the junction. However, 

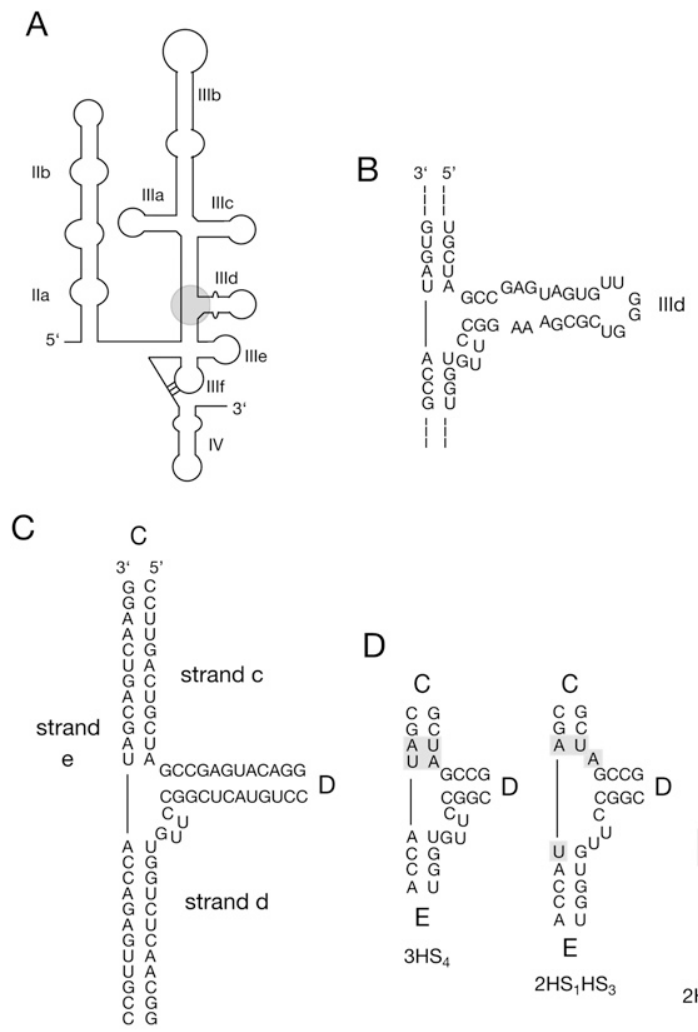

E

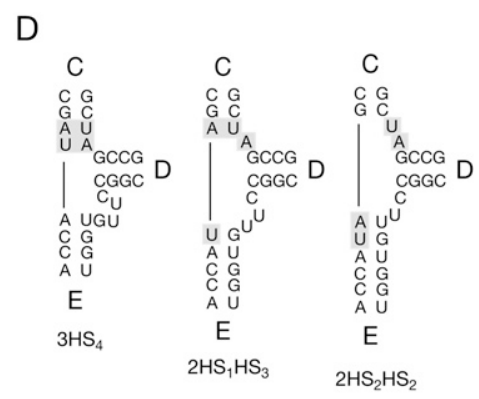

FIGURE 1. The hepatitis $C$ virus IRES. (A) Schematic of the secondary structure of the IRES. The three-way helical junction studied here is circled. (B) The local sequence around the three-way junction containing helix IIId. (C) The sequence of the three-way junction in the form studied here. The junction comprises three strands (c, d, and e) and the arms are labeled C, D, and E as shown. The loop and non-WatsonCrick pairs have been removed from helix IIId to create a simple helix $\mathrm{D}$ for the majority of this study. (D) A form of branch migration creates three possible secondary structures at the junction.

it has been demonstrated that the apical GGG is critical for the IRES function (Kieft et al. 1999), as it seems to be essential for binding by the $40 \mathrm{~S}$ ribosomal subunit. Since the conformation of the junction will likely determine the presentation of this loop to the ribosome, we expect that the junction will be critical to IRES function.

Helical junctions are a major structure determinant of complex RNA species (Lilley 2000). Their geometry orients helices relative to one another, allowing long-range tertiary contacts to occur. For example, inspection of the structures of the $16 \mathrm{~S}$ and $23 \mathrm{~S}$ rRNA species within the ribosome reveals many helical junctions (Ban et al. 2000; Wimberly et al. 2000). The structure of some autonomously folding smaller RNA species can be almost entirely determined by component junctions (Murchie et al. 1998; Walter et al. 1998), as exemplified by the VS ribozyme where the structural core of the ribozyme comprises five helical segments related by two three-way junctions (Lafontaine et al. 2002; Lipfert et al. 2008). Helical junctions can also generate the catalytic center of ribozymes, such as the hammerhead ribozyme (Martick et al. 2008), and ligand binding pockets of great selectivity, as found in a number of riboswitches (Serganov et al. 2004, 2008; Garst et al. 2008). Three-way junctions are especially common in functional RNA species of all sizes. In the sections that follow we set out a new analysis of the structure and topology of three-way junctions in general, and then follow this with a discussion of the specific sequence of the IRES three-way junction.

The helical arms of junctions in both DNA and RNA have a strong propensity to undergo coaxial stacking when electrostatic repulsion is minimized by the presence of metal ions (Duckett et al. 1988, 1995; Orr et al. 1998; Walter et al. 1998; Lescoute and Westhof 2006; de la Pena et al. 2009). In the case of three-way junctions, only two arms can be stacked in this way, and the third must remain unstacked. The simplest case is the perfectly base-paired $3 \mathrm{H}$ junction, where the three interhelical connections each lack additional nucleotides. However, $3 \mathrm{H}$ junctions are rare in natural RNA species, and most have at least one connecting segment comprising one or more unpaired nucleotides, which we term "linking" nucleotides. These probably provide conformational flexibility that is essential to allow the junctions to fold by pairwise coaxial stacking. Examination of the structures of three-way junctions observed in crystal structures of RNA species (Lescoute and Westhof 2006) indicates a strong propensity of junctions fold in a way that minimizes the number of linking nucleotides between the stacked helices. This is a reliable predictor of structure in natural three-way junctions. A junction with two coaxially stacked helices is depicted schematically in Figure 2A. It should be noted that all three component strands are structurally distinct. One strand runs the length of the stacked helices-we call this strand "continuous" (con). The other two pass between the stacked helices and the third helix. One passes out of the stack in a $5^{\prime}$-to-3' direction-we call this "exit" (ex). The other passes in the opposite direction, and we call this "entry" (en). In a junction that has a single linking segment, the linker (L) can be located on either the ex strand (termed the Lex form), or on the en strand (termed Len) (Fig. 2B). These correspond to the Westhof structural families A and C, respectively (Lescoute and Westhof 2006). It is important to note that because the ex and en strands are inequivalent, the Lex and Len structures are also inequivalent (unlike the two stacking conformers of a four-way junction), and are likely to have different stabilities. Where there are two linkers of equal length we term this "equal" (Leq); this corresponds to the Westhof family B (Lescoute and Westhof 2006).

The orientation of the third helix in the plane of the three helices can also be specified with respect to the direction of the con strand. It can be directed toward the $3^{\prime}$ end, so that the axes of the ex strand subtend an acute angle, or it can be directed toward the $5^{\prime}$ end, in which case it is the en strand whose axes make an acute angle. Alternatively, the third helix could be approximately perpendicular to the axis of the stacked helix. 


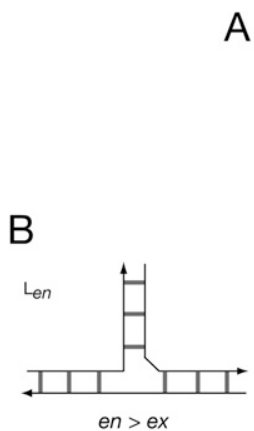

A
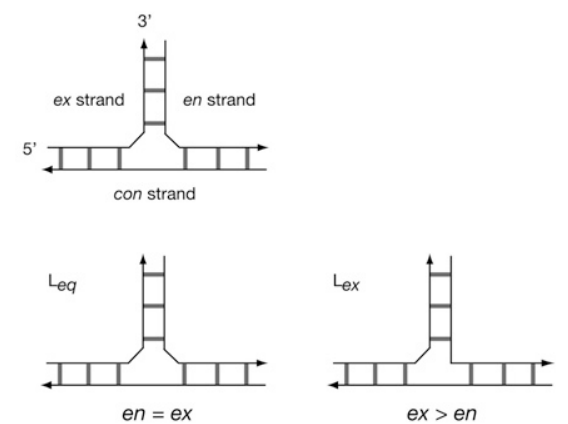

C
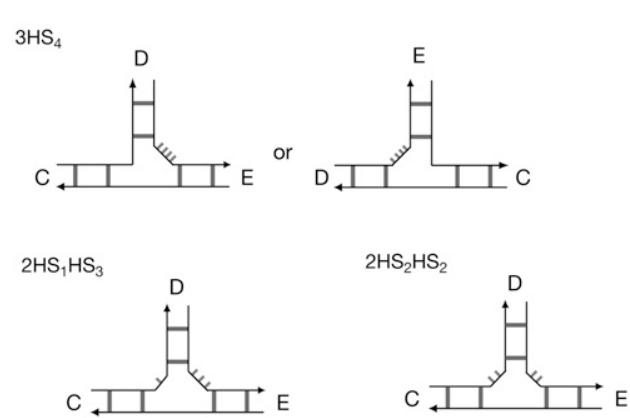

FIGURE 2. The structurally distinct strands of three-way junctions with formally unpaired linking segments, and possible structures for the IRES junction. (A) The component strands of a three-way junction with two coaxially stacked helices are distinct. The con strand turns about the shared axis of the stacked helices, while the en and ex strands have their $5^{\prime}$ and $3^{\prime}$ termini in the nonstacked helix. $(B)$ Three possible forms of a junction with unpaired RNA linking the unstacked helix to the coaxially stacked pair of helices. If the linker (or longer linker where there are two) lies on the en or ex strand, we term the structures Len or Lex, respectively, while if there are two linking segments of equal length we call it Leq. (C) In principle the three-way junction of the IRES might adopt alternative secondary structures, so there are a number of structures possible. The $3 \mathrm{HS}_{4}$ secondary structure has a single segment linking the $\mathrm{D}$ and $\mathrm{E}$ arms, and could therefore adopt either Len (C-on-E stacking) or Lex (D-on-C stacking) structures in principle, or both in equilibrium. The $2 \mathrm{HS}_{1} \mathrm{HS}_{3}$ or $2 \mathrm{HS}_{2} \mathrm{HS}_{2}$ structures would be expected to fold by C-on-E stacking, forming Len and Leq structures, respectively.

In the present study we have examined the HCV IRES three-way junction that includes helix IIId. Since the terminal loop of helix IIId binds to the 40S ribosomal subunit (Kolupaeva et al. 2000; Kieft et al. 2001; Boehringer et al. 2005), and certain mutations in the loop and internal bulge can abolish HCV IRES binding (Jubin et al. 2000; Klinck et al. 2000; Kieft et al. 2001), the structure of the junction and the resulting trajectory of helix $\mathrm{D}$ are likely to be important to the function of the IRES element. For this work we have named the component helices $\mathrm{C}$ (the upper arm from which extend helices IIIa, IIIb and IIIc), D (helix IIId), and E (the lower arm that includes IIIe and IIIf) (Fig. 1C). The base pairing is conventionally drawn in the form of a $3 \mathrm{HS}_{4}$ junction. However, we note that the base pairing could be rearranged slightly to create either $2 \mathrm{HS}_{1} \mathrm{HS}_{3}$ or $2 \mathrm{HS}_{2} \mathrm{HS}_{2}$ junctions (Fig. 1D). In principle, the junction could undergo two steps of branch migration, with the $3 \mathrm{HS}_{4}$ and
$2 \mathrm{HS}_{2} \mathrm{HS}_{2}$ junctions as the extremes. These three forms are unlikely to be of equal free energy, but in the absence of experimental data, we cannot predict which might be the more stable. However, the secondary structure will have a major influence on the fold adopted by the junction.

The $3 \mathrm{HS}_{4}$ structure has a single linking segment of $4 \mathrm{nt}$, and two connections with zero length linkers. There are, therefore, two possible structures that might be adopted in which either helices $\mathrm{C}$ and $\mathrm{E}$, or helices $\mathrm{D}$ and $\mathrm{C}$, are coaxially stacked (Fig. 2C). Note that these are not equivalent, as they are Len and Lex structures, respectively. Indeed, Lescoute and Westhof (2006) speculated that the structure of this junction might fall into either family $\mathrm{A}$ or $\mathrm{C}$ on the basis of the $3 \mathrm{HS}_{4}$ structure. However, if the junction adopts either the $2 \mathrm{HS}_{1} \mathrm{HS}_{3}$ or the $2 \mathrm{HS}_{2} \mathrm{HS}_{2}$ secondary structure, there would be two linking segments, and thus only one way of stacking two arms without a linker. In this structure helices $\mathrm{C}$ and $\mathrm{E}$ are coaxially stacked. The $2 \mathrm{HS}_{1} \mathrm{HS}_{3}$ junction is a Len structure, while the $2 \mathrm{HS}_{2} \mathrm{HS}_{2}$ form is a Leq structure (Fig. 2C).

From this analysis either secondary structure could adopt the structure based on $\mathrm{C}$ upon $\mathrm{E}$ coaxial stacking. However, it is likely that the orientation of the D arm (and thus its interaction with the ribosome) would depend on which secondary structure is formed. In this study we have examined the conformation of the IRES junction using a combination of comparative gel electrophoresis and fluorescence resonance energy transfer (FRET) in both ensemble steady-state and single-molecule mode. It emerges that in addition to its functional significance, the IRES junction is an interesting test of the conformational principles of threeway helical branch points, requiring a consideration of both secondary and three-dimensional structure.

\section{RESULTS}

\section{Analysis of interhelical angles in the IRES three-way junction}

We have studied the structure of the three-way junction shown in Figure 1B. The component helices of the junction are Watson-Crick paired for at least three base pairs extending outward from the point of strand exchange. Helix IIId contains a number of formal non-Watson-Crick pairs, and a small internal loop; however, an NMR structure showed this to be essentially helical without major axial perturbation despite the non-Watson-Crick pairs (Lukavsky et al. 2000). For the major part of this analysis we have therefore retained the central sequence of the junction and extended its arms with perfectly paired helices (Fig. 1C), although we return to the natural sequence later. In this study we have named the helical arms $C, D$, and $\mathrm{E}$ as shown, where helix D is equivalent to helix IIId in the complete IRES. The strands are labeled by lower case letters that correspond to the arm in which the $5^{\prime}$ terminus is located. This junction has 
been analyzed using comparative gel electrophoresis and FRET.

\section{Analysis of interhelical angles in the IRES three-way junction using comparative gel electrophoresis}

Comparative gel electrophoresis provides a simple yet powerful way to examine the global conformation of a helical junction in RNA under a variety of conditions (Lilley 2008, 2009a). The IRES junction was constructed from three separate strands (each generated by transcription from a DNA template), and prepared in different forms comprising the three possible variants with two long (40 base pairs [bp]) arms and one shortened (10 bp) arm. The species are named according to the long arms; e.g., CD has long C and D arms, and a shortened arm E. The relative electrophoretic mobility in polyacrylamide gels of the three long-short arm species reflects the angle subtended between the two long arms.

The three species of the IRES junction have been electrophoresed in $10 \%$ polyacrylamide gels under a variety of ionic conditions (Fig. 3). In the absence of added metal ions (with $2 \mathrm{mM}$ EDTA to chelate any traces of metal ions), the three species migrate with relative rates of $\mathrm{DE}>\mathrm{CE}>$ $\mathrm{CD}$. This indicates that the largest angle contains the formally unpaired CUUG sequence, suggesting a conformation with an open center. The smallest angle is subtended between the $\mathrm{C}$ and $\mathrm{D}$ arms. Upon addition of metal ions the pattern of electrophoretic mobility is significantly changed, with relative rates $\mathrm{CE}>\mathrm{DE}>\mathrm{CD}$. Thus, in common with many helical junctions, the IRES three-way junction undergoes a metal ion-induced change in conformation. The fast mobility of the CE species would be consistent with a predominant species present in a solution whose structure is based upon coaxial stacking of the $\mathrm{C}$ and $\mathrm{E}$ helices, with the e strand passing continuously between the two helices through the junction. The relative mobilities of the remaining species indicated that helix $\mathrm{D}$ is directed into the same quadrant as helix $\mathrm{C}$. The global structure is apparently closely similar in $1 \mathrm{mM} \mathrm{Mg}^{2+}$ and $25 \mathrm{mM} \mathrm{Na}^{+}$ions, suggesting that specific ion binding may not be required to fold the junction. The same global geometry is also found in the presence of the trivalent ion $\left[\mathrm{Co}\left(\mathrm{NH}_{3}\right)_{6}\right]^{3+}$.

\section{Analysis of relative end-to-end distances of the arms of the IRES three-way junction using steady-state fluorescence resonance energy transfer}

FRET is an alternative way to analyze the global structure of helical junctions in solution, based on energy transfer between donor and acceptor fluorophores attached to the ends of selected pairs of helical arms (Lilley 2009b). Efficiency of the process depends inversely on the sixth power of the distance between the fluorophores (Förster 1948). The IRES junction was constructed with three arms, each

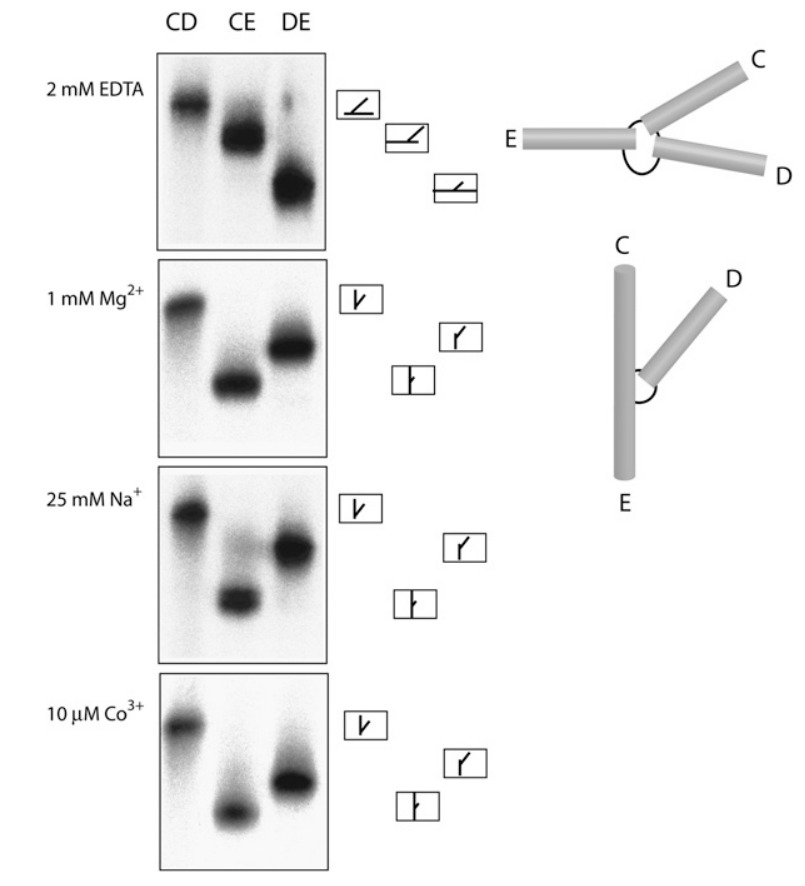

FIGURE 3. Comparative gel electrophoresis of the conformation adopted by the three-way junction of the HCV IRES in different ionic conditions. The junction studied had a simplified helix D, with the central sequence shown in Figure 1C. Three forms of the junction, each with a different helical arm shortened, are electrophoresed in adjacent tracks of a $10 \%$ polyacrylamide gel in the presence of $90 \mathrm{mM}$ Tris-borate ( $\mathrm{pH} 8.3$ ) with the indicated metal ions (or EDTA to chelate metal ions). The long-short-arm junction species are named according to the two long arms. An interpretation of the structures adopted is shown on the right, together with the anticipated structures and mobilities of the long-short-arm junction species. In the presence of EDTA the slow-intermediate-fast pattern is interpreted in terms of the extended structure, while the slow-fast-intermediate pattern observed in the presence of metal ions is interpreted in terms of a structure in which helices $\mathrm{C}$ and $\mathrm{E}$ are coaxially stacked, with an acute angle subtended between helices $\mathrm{C}$ and D.

comprised of 12 bp (when drawn with $3 \mathrm{HS}_{4}$ secondary structure), labeled with fluorescein donor and Cy3 acceptor attached via the $5^{\prime}$-termini of different strands (Fig. 4). Fluorescein attached at the $5^{\prime}$-terminus is relatively mobile (Norman et al. 2000). This minimizes the complications of fluorophore orientation, so that a simple interpretation based on an inverse relationship between FRET efficiency and distance is unlikely to be misleading. Three such species were constructed, corresponding to the vectors (named according to the arms carrying the donor and acceptor, in that order) $\mathrm{CD}, \mathrm{CE}$, and $\mathrm{DE}$.

FRET efficiency for the three vectors was measured in the steady state as a function of $\mathrm{Mg}^{2+}$ ion concentration (Fig. 4). This clearly confirms that the structure of the IRES junction depends on the metal ion concentration. The relative interfluorophore distances at low ionic concentration are $\mathrm{DE}>\mathrm{CE}>\mathrm{CD}$, fully consistent with the global structure deduced from comparative gel electrophoresis. Furthermore, the relative distances in the presence of $\geq 1 \mathrm{mM}$ 


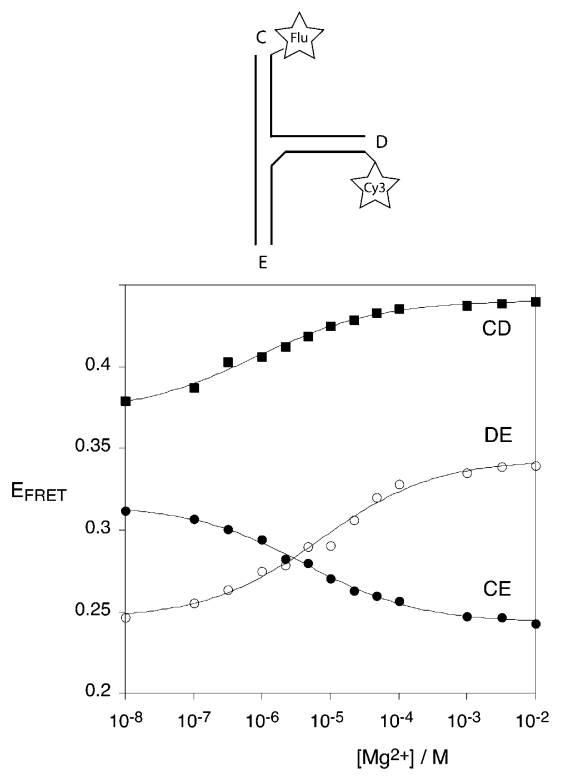

FIGURE 4. Analysis of metal ion-induced folding of the IRES threeway junction by steady-state FRET measurements. The junction shown in Figure 1C was prepared with fluorescein (donor) and Cy3 (acceptor) fluorophores attached to the $5^{\prime}$-termini of selected helical arms. These vectors are named by the labeled arms, in the order donor-acceptor, so that the $\mathrm{CD}$ vector has fluorescein attached to helix $\mathrm{C}$ and $\mathrm{Cy} 3$ to helix D. FRET efficiency was measured using the acceptor normalization procedure as a function of $\mathrm{Mg}^{2+}$ ion concentration in $90 \mathrm{mM}$ Tris-borate $(\mathrm{pH} \mathrm{8.3)}$, and plotted for the three vectors $\mathrm{CD}(\boldsymbol{\square}), \mathrm{DE}(\mathrm{O})$, and $\mathrm{CE}(\boldsymbol{\bullet})$. The data have been fitted to a two-state model of ion-induced folding (-).

$\mathrm{Mg}^{2+}(\mathrm{CE}>\mathrm{DE}>\mathrm{CD})$ are also consistent with the structure of the predominant species from the electrophoretic experiments in the presence of metal ions. The titrations can be fitted to a two state transition in which the junction folds in response to the binding of $\mathrm{Mg}^{2+}$ ions. Analysis of the data for the $\mathrm{CE}$ and $\mathrm{DE}$ vectors give half-magnesium concentrations of $\left[\mathrm{Mg}^{2+}\right]_{1 / 2}=4$ and $7 \mu \mathrm{M}$, respectively. Hill coefficients of 0.52 for both vectors indicate an anti-cooperative process under these conditions, consistent with folding induced by the diffuse interaction of metal ions.

\section{Analysis of the conformation population of the IRES three-way junction using single-molecule FRET}

Although electrophoresis and steady-state FRET indicate a predominant conformation that is probably based upon coaxial stacking of $\mathrm{C}$ on $\mathrm{E}$ arms, these experiments could not exclude a small population of an alternative conformer in equilibrium. We therefore searched for such a conformation using single-molecule FRET experiments. We studied the CE and $\mathrm{CD}$ vectors, using $\mathrm{Cy} 3$ and $\mathrm{Cy} 5$ as donor and acceptor fluorophores, respectively (Fig. 5). In addition, we prepared an identically labeled 24-bp duplex species by hybridization of the e strand to its complement, as a model for $\mathrm{C}$ and $\mathrm{E}$ arms that are coaxially stacked. All species were studied as single junction molecules encapsulated in phospholipid vesicles in the presence of $10 \mathrm{mM} \mathrm{Mg}^{2+}$ ions, using prism-based total internal reflection fluorescence microscopy. Time traces of donor and acceptor intensities were recorded at time resolutions between 100 and $8 \mathrm{msec}$, for hundreds of single junctions, and histograms of FRET efficiency were calculated after filtering anomalous data (see Materials and Methods).

$E_{\text {FRET }}$ histograms of data at 100 -msec resolution for the junction and duplex species are presented in Figure 5. The $\mathrm{CD}$ and $\mathrm{CE}$ vectors of the junction give distributions that are well fitted by single Gaussian curves, with mean $E_{\text {FRET }}$ values of 0.62 and 0.29 , respectively (Table 1 ). These values are qualitatively in good agreement with the model resulting from the electrophoresis and steady-state FRET data. Moreover, the value for the $\mathrm{CE}$ vector is similar to that of the simple CE duplex $\left(E_{\mathrm{FRET}}=0.32\right)$, as would be expected if the $\mathrm{C}$ and $\mathrm{E}$ arms were coaxially stacked in the folded junction. The widths of both distributions for the junction species are not much greater than that for the duplex,

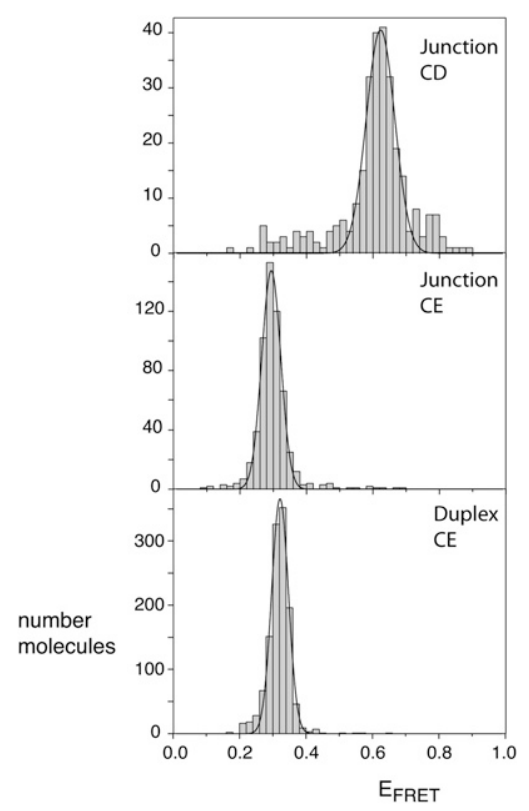

FIGURE 5. Population distributions of FRET efficiencies for Cy3Cy5-labeled IRES junctions studied as single molecules. Except for the different fluorophores, equivalent junction species as used in the steady-state fluorescence experiments (Fig. 4) were studied. In addition, a Cy3-Cy5-labeled duplex was prepared by hybridization of the junction e strand to its complement, to provide a model for coaxially stacked $\mathrm{C}$ and $\mathrm{E}$ arms. The different species were encapsulated in phospholipid vesicles in $10 \mathrm{mM}$ Tris- $\mathrm{HCl}$ (pH 8.1), $50 \mathrm{mM} \mathrm{NaCl}, 10 \mathrm{mM}$ $\mathrm{MgCl}_{2}$, and imaging buffer (see Materials and Methods) and studied by total internal reflection fluorescence microscopy. Hundreds of single molecules were studied for each species, and fluorescent intensities at Cy3 and Cy5 emission wavelengths recorded for a number of minutes with a $100-\mathrm{msec}$ resolution. Molecules with aberrant spectral properties were rejected and FRET efficiencies calculated from the remainder. These were plotted as the histograms shown, fitted to Gaussian distributions. Histograms are shown for the $\mathrm{CD}$ junction, the $\mathrm{CE}$ junction, and the CE duplex. The measured mean $E_{\mathrm{FRET}}$ and half-widths for each distribution are presented in Table 1 . 
TABLE 1. Conformational populations for the different Cy3-Cy5 vectors constructed from the IRES junction with helix $D$ in its simplified and natural forms calculated from single-molecule FRET experiments

\begin{tabular}{|c|c|c|c|}
\hline Species & $E_{\mathrm{FRET}}$ & Half-width & $\begin{array}{l}\text { Number } \\
\text { of } \\
\text { molecules }\end{array}$ \\
\hline \multicolumn{4}{|c|}{ Simplified helix D } \\
\hline Vector CD & $0.62 \pm 0.002$ & $0.086 \pm 0.004$ & 287 \\
\hline Vector CE & $0.29 \pm 0.0005$ & $0.057 \pm 0.001$ & 577 \\
\hline Duplex DE & $0.32 \pm 0.0004$ & $0.050 \pm 0.004$ & 1226 \\
\hline \multicolumn{4}{|c|}{ Natural helix D } \\
\hline Vector CD & $0.46 \pm 0.0006$ & $0.062 \pm 0.001$ & 1693 \\
\hline Vector CE & $0.30 \pm 0.0005$ & $0.052 \pm 0.001$ & 860 \\
\hline
\end{tabular}

indicating that the arms of the junction do not undergo flexural motions of large amplitude. The data for the CD vector has points that are distributed over a wider range of FRET than the Gaussian fit, but these are likely to have arisen from the smaller number of molecules analyzed compared with the CE species.

Importantly, we see no evidence of additional populations of $E_{\mathrm{FRET}}$, i.e., donor-acceptor distance. In the histogram for the $\mathrm{CE}$ vector there is no detectable peak at higher values of $E_{\mathrm{FRET}}$. In the $\mathrm{CD}$ vector histogram we observe some points at $E_{\mathrm{FRET}}=0.3$, but they are randomly distributed rather than forming a distinct peak. Similar histograms were calculated from the data recorded at a faster acquisition time. These data provide no evidence for a minor conformation present in solution under these conditions.

\section{No conformational transitions have been detected in the IRES three-way junction using single-molecule FRET}

As a further way of seeking alternative conformations, we examined the time records for many single junction molecules, looking for anti-correlated changes in donor and acceptor intensities that would indicate a transition to a different structure. At $100-\mathrm{msec}$ time resolution we can follow donor and acceptor fluorescent intensities over 200 $\mathrm{sec}$ or more before photobleaching. Examples of $\mathrm{CD}$ and $\mathrm{CE}$ vectors are shown in Figure 6, A and C, respectively, with their corresponding FRET efficiency histograms in $\mathrm{B}$ and $\mathrm{D}$, respectively. There is no evidence for any structural transition involving a change of FRET efficiency in these traces, and we found very few examples of a transition in the hundreds of time traces examined.

We also sought short-lived conformational states by examining time traces recorded in the presence of $10 \mathrm{mM}$ $\mathrm{MgCl}_{2}$ at 8-msec time resolution; the highest possible using our EMCCD camera. A 1-sec section of a trace for the CD vector is expanded in Figure 6E. No evidence in this trace (or in many others studied) can be seen for anti-correlation of Cy3 and Cy5 intensities. This is further demonstrated by calculating a cross-correlation function from a randomly chosen $4 \mathrm{sec}$ of data (Fig. 6F). These data show no indication of a decaying anti-correlation, fitting a linear, horizontal function passing through zero. A small subset of junction species (three molecules out of a total of 323) underwent multiple slow transitions between states of different FRET efficiencies; these molecules are clearly of a different character from the majority and are likely to be misfolded or mishybridized junctions.

In summary, using faster acquisition and cross-correlation analysis we have found no evidence for an additional conformation of the junction.

\section{Studying the secondary structure of the IRES three-way junction using in-line probing}

In view of the uncertainty with regard to the secondary structure adopted by the IRES three-way junction, we performed in-line probing experiments in an attempt to identify conformationally flexible nucleotides within the core. In this approach, radioactively $\left[5^{\prime}-{ }^{32} \mathrm{P}\right]$-labeled RNA is subjected to a prolonged incubation in the presence of buffer and $\mathrm{Mg}^{2+}$ ions. Where the backbone is relatively flexible, the RNA can sample a conformation in which the $2^{\prime}-\mathrm{OH}$ may carry out an in-line nucleophilic attack on the $3^{\prime}$-phosphate, but this is hindered in more rigid parts of the molecule, including duplex regions. Using transcription by T7 RNA polymerase, we prepared two constructs both of which comprised a single strand of RNA, with terminal hairpin loops on either the $\mathrm{C}$ and $\mathrm{E}$ or the $\mathrm{D}$ and $\mathrm{E}$ helices (Fig. 7) in order to maximize the resolution of the sequences of interest by gel electrophoresis.

As expected, the data reveal that the nucleotides of the loops are flexible. But interestingly, this analysis shows quite clearly that there are two regions of flexibility in the core of the junction. The center of the strand linking the $\mathrm{C}$ and $\mathrm{E}$ helices (i.e., what would be the e strand if the junction comprised three separate strands) exhibits no detectable reactivity, consistent with the coaxial stacking of the $\mathrm{C}$ and $\mathrm{E}$ arms. However, the remaining two linking regions do exhibit reactivity, with a single point of cleavage between the $\mathrm{C}$ and $\mathrm{D}$ arms (equivalent to the $\mathrm{c}$ strand), clearly visible in Figure 7A, and four consecutive cleavages between D and E (equivalent to the $\mathrm{d}$ strand), seen most clearly in Figure 7B. These data suggest that the predominant form of the junction is $2 \mathrm{HS}_{1} \mathrm{HS}_{3}$, although we do not believe that is conclusive. We considered repeating the analysis with junctions in which the secondary structure is locked into place, but this would require changes of sequence at the center of the junction that might well alter the folding significantly. At the present time the most probable conclusion from our data is that the junction is the $2 \mathrm{HS}_{1} \mathrm{HS}_{3}$ structure, but it is possible that branch migration occurs that generates a 
A

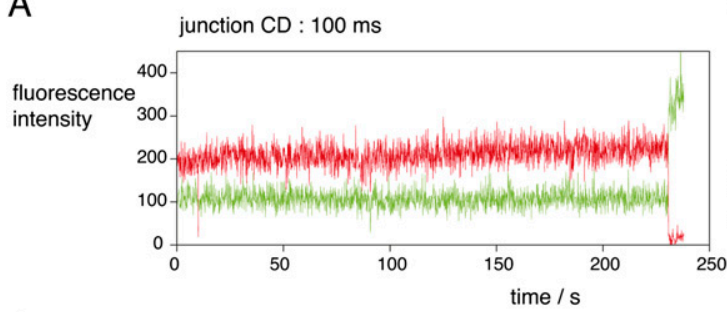

C

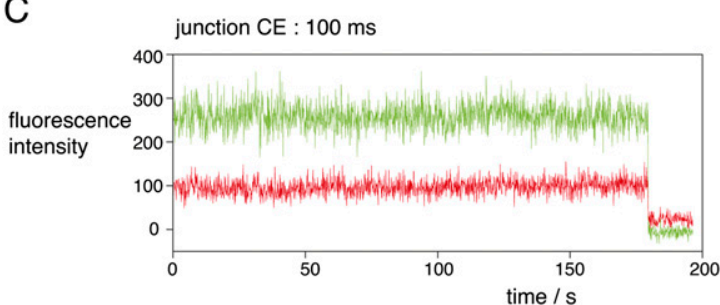

E

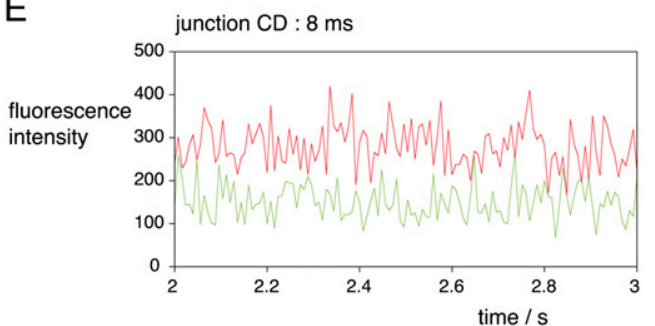

B

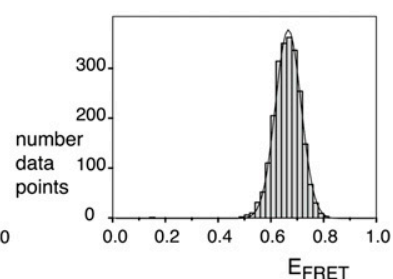

D

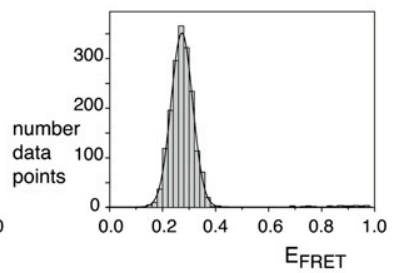

$\mathrm{F}$

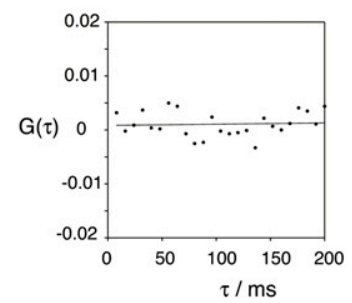

FIGURE 6. Seeking conformational transitions in single-junction molecules. The CD and CE vectors (the same species used in Figure 5) were separately encapsulated in phospholipid vesicles in $10 \mathrm{mM}$ Tris- $\mathrm{HCl}(\mathrm{pH} 8.1), 50 \mathrm{mM} \mathrm{NaCl}, 10 \mathrm{mM} \mathrm{MgCl} 2$, and imaging buffer, and studied by total internal reflection microscopy. Representative long time records at 100 -msec time resolution are shown for the $\mathrm{CD}$ and $\mathrm{CE}$ vectors ( $A$ and $C$, respectively) up to the point at which fluorophore photobleaching has occurred. Histograms of $E_{\mathrm{FRET}}$ for the individual CD and $C E$ molecules are also presented as plots $B$ and $D$, respectively, for the unbleached sections of the time records. Note that no transitions can be detected over these long time traces. The same preparation of $\mathrm{CD}$ vector was also studied at $8-\mathrm{msec}$ time resolution. A 1-sec section of a time record is presented $(E)$. Close examination of this (and many other traces not shown) fails to reveal anti-correlation between $\mathrm{Cy} 3$ and $\mathrm{Cy} 5$ fluorescence intensity. This is confirmed by performing a cross-correlation analysis on a 4 -sec time record $(F)$. The data fit a linear function with no decay, passing through zero.

population of the other forms if this did not alter the global folding of the junction.

\section{Restoration of the natural secondary structure of helix D does not significantly perturb the structure of the junction}

In the natural form of the junction the secondary structure of helix D contains an internal loop and a number of nonWatson-Crick base pairs after the third base pair from the junction. These were removed from the junction studied above to provide a regular helix to facilitate the analysis. An NMR study of a stem-loop with the sequence of helix D reveals it to adopt the general structure of an A-form helix in broad terms, but in principle, nucleotides from the helix might interact with those of the junction and alter its gross structure or induce transitions between alternative structures. To test this possibility we repeated the single-

molecule analysis on a new form of the junction in which the natural structure was restored to arm D. The UUGGGU terminal loop was replaced by four additional base pairs, and the vectors $\mathrm{CD}$ and $\mathrm{CE}$ were prepared by addition of 5'-linked $\mathrm{Cy} 3$ and $\mathrm{Cy} 5$ fluorophores as before (Fig. 8A).

The results from the single-molecule FRET analysis are qualitatively similar to those from the junction with a regular helix D. The histograms for the two vectors both reveal a single peak of FRET efficiency, with CD > CE (Fig. 8B). The $E_{\text {FRET }}$ value for the CE vector (0.30) (Table 1) is slightly greater than that observed for the simplified junction (0.29), but still very much in the range expected for a coaxial C-E alignment. The half-widths are also similar. The structure of the natural junction is therefore likely to be based on C-on-E helix stacking. However, the $E_{\mathrm{FRET}}$ of the $\mathrm{CD}$ vector is significantly lower than that for the simplified junction. This might result from a reorientation of helix $\mathrm{D}$ arising from new interactions with unpaired bases in that helix. But there are other potential origins for different FRET efficiencies between the two vectors. The D helix in the modified junction is longer than that of the simplified junction by $3 \mathrm{bp}$, and the Cy5 position is likely to be rotationally different between the two with consequent differences in the relative orientation of the fluorophore transition moments, which can significantly influence FRET efficiency (Iqbal et al. 2008a). Even if orientational effects were unimportant, the FRET efficiency corresponds to a distance that is comparable to the likely Förster length $R_{0}$, where a relatively small change in distance can result in a significant change in $E_{\text {FRET }}$. As with the simplified junction, we observe no anticorrelated changes in fluorescent intensity between donor and acceptor for either vector (Fig. 8C), providing no evidence for structural transitions in the junction.

\section{DISCUSSION}

The three-way junction of the HCV IRES element turns out to be an interesting object lesson in the conformational possibilities of RNA branch points. Like most nucleic acid junctions, it requires the presence of metal ions to fold from an extended form to a form based on pairwise coaxial stacking of helical arms. The transition is induced by $\mathrm{Mg}^{2+}$ 
A

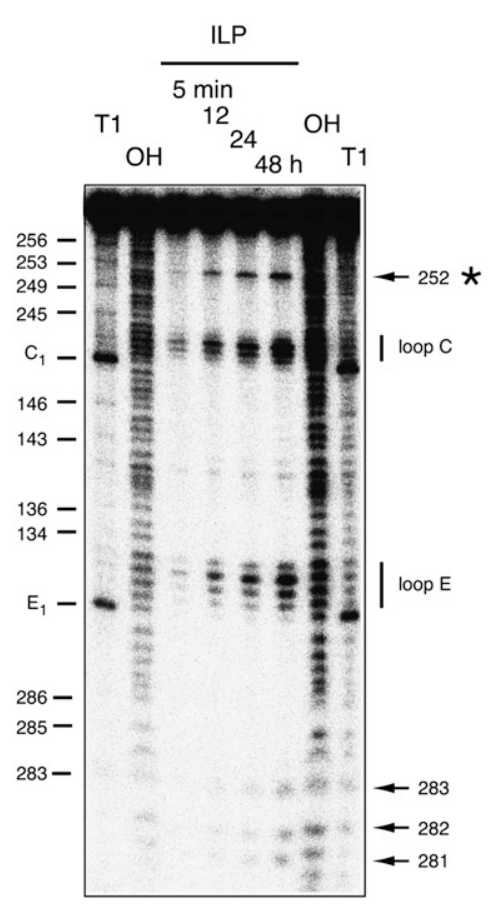

B

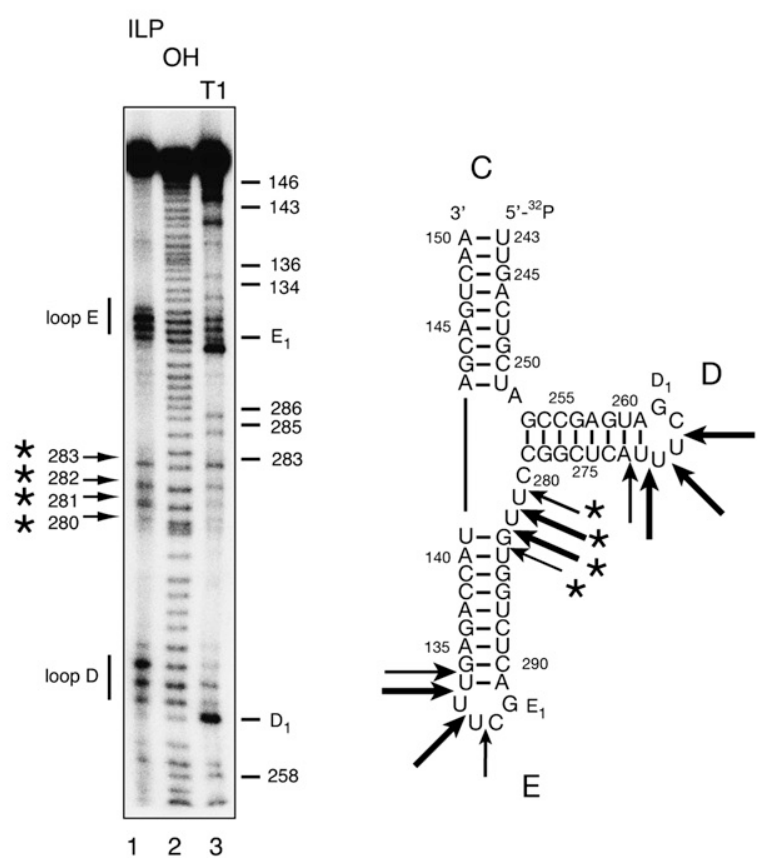

FIGURE 7. Analysis of the structural flexibility of nucleotides in the IRES three-way junction using in-line probing. Radioactively [ $\left.5^{\prime}-{ }^{32} \mathrm{P}\right]-$ labeled RNA was incubated in $50 \mathrm{mM}$ Tris- $\mathrm{HCl}(\mathrm{pH} 8.3), 100 \mathrm{mM} \mathrm{KCl}$, and $20 \mathrm{mM} \mathrm{MgCl}_{2}$ for various times at $21^{\circ} \mathrm{C}$, and analyzed by denaturing gel electrophoresis and phosphorimaging. The junction was studied as a single strand by placing terminal loops onto two helices. In order to maximize the resolution of the sequences of interest, two constructs were studied, each with a single $5^{\prime}$-terminus in either helix $\mathrm{D}(A)$ or helix $\mathrm{C}$ $(B)$. Bands were assigned by reference to cleavage by ribonuclease T1 $(A$, lanes 1,$8 ; B$, lane 3$)$ and a hydroxide cleavage ladder $(A$, lanes 2,$7 ; B$, lane 2). The junction with open helix $\mathrm{D}$ was subjected to in-line probing for $5 \mathrm{~min}, 12,24$, and $48 \mathrm{~h}$ ( $A$, lanes 3-6, respectively), and the open $\mathrm{C}$ arm form to a 48 -h incubation ( $B$, lane 1). The nucleotides were numbered according to Honda et al. (1999).

ions in low micromolar concentrations, with a Hill coefficient suggestive of nonspecific binding. But the major interest lies in the structure adopted in the presence of metal ions.

Comparative gel electrophoresis and steady-state FRET studies clearly indicate that in the presence of metal ions the junction predominantly adopts a conformation in which arms $\mathrm{C}$ and $\mathrm{E}$ could be colinear, with an acute angle subtended between arms $\mathrm{C}$ and $\mathrm{D}$. The similarity in FRET efficiency between the $\mathrm{CE}$ vector of the junction measured in single junction molecules, and a duplex made by hybridizing the e strand to its complement, is consistent with the coaxial stacking of the $\mathrm{C}$ and $\mathrm{E}$ arms in the folded junction. The half-width of the length distribution for the $\mathrm{CE}$ vector of the junction is only a little greater than that of the duplex, indicating that the center of the junction is not very flexible. The mean FRET efficiency is slightly lower for the junction $\left(E_{\mathrm{FRET}}=0.29\right)$ compared with the perfect duplex $\left(E_{\mathrm{FRET}}=0.32\right)$. While a rotation of the $\mathrm{C}$ and $\mathrm{E}$ arms hinged about the center would shorten the end-to-end distance and have a relatively small effect on fluorophore orientation, there are two ways in which the efficiency might be reduced compared with the duplex. First, if these arms were unstacked and pulled apart to dislocate the junction, this could increase the end-to-end distance in the junction. Second, a rotation of the helical arms about their common axis might lead to a change in $\kappa^{2}$ that gives a lower $E_{\mathrm{FRET}}$. It is known that $\mathrm{Cy} 3$ and $\mathrm{Cy} 5$ fluorophores may be stacked onto the helical ends of nucleic acid duplexes (Norman et al. 2000; Iqbal et al. 2008b) resulting in significant modulation of energy transfer due to the orientation of their transition dipole moments (Iqbal et al. 2008a). However, the manner of fluorophore attachment to the RNA is not the same as was used in that study, so we cannot be certain about the nature of the RNA-fluorophore interaction in the present case. Both these effects might occur, each contributing to the lower observed $E_{\mathrm{FRET}}$ of the junction compared with the perfect duplex.

If the junction significantly populated the $3 \mathrm{HS}_{4}$ secondary structure, it is possible that a subfraction would adopt an alternative conformer in which D and $\mathrm{C}$ arms are stacked (Fig. 2C). No minor fraction could be detected using singlemolecule FRET, nor were any transitions to such a species observed in the hundreds of single molecules studied. If an alternative conformer exists, it must have a lifetime that is significantly shorter than $8 \mathrm{msec}$. However, such a fast exchange situation is unlikely. If a small population of the $\mathrm{D}$-on-C stacked conformer was in fast equilibrium with the 

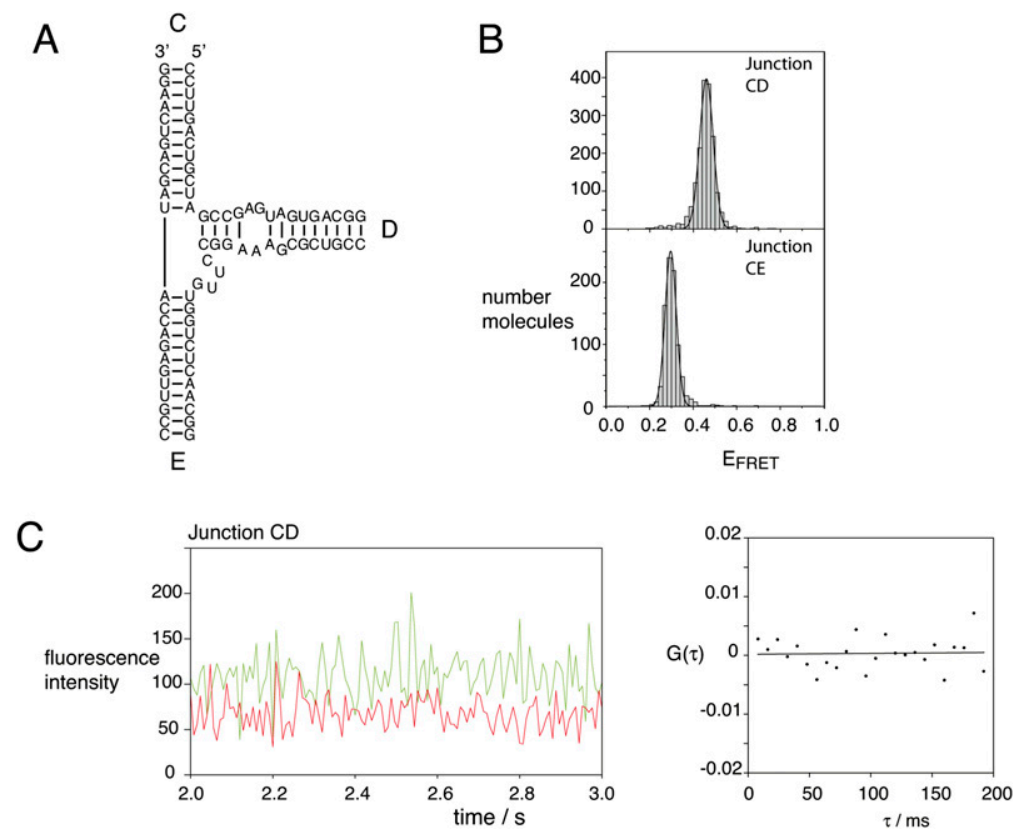

FIGURE 8. Single-molecule FRET analysis of the three-way IRES junction with helix D of the natural sequence. $(A)$ The sequence of the junction studied. This is identical to that of the simplified junction except for the restoration of the base pairing found in the natural junction. However, the terminal loop was removed and the base pairing extended to form a stable helix with a $5^{\prime}$-terminus for fluorophore attachment. The junction is formally depicted in the $3 \mathrm{HS}_{4}$ secondary structure. (B) Population distributions of FRET efficiencies for Cy3-Cy5-labeled vectors encapsulated in phospholipid vesicles in $10 \mathrm{mM}$ Tris- $\mathrm{HCl}(\mathrm{pH} 8.1), 50 \mathrm{mM} \mathrm{NaCl}, 10$ $\mathrm{mM} \mathrm{MgCl}$, and imaging buffer measured at $100-\mathrm{msec}$ time resolution. The total number of molecules included were 1693 and 860 for the CD and CE vectors, respectively. (C) A representative 1 -sec time record for the $\mathrm{CD}$ vector at 8 -msec resolution (left). Four seconds of data were used as input into a cross-correlation analysis (right). These data show no evidence of structural transitions at this time resolution.

majority C-on-E form, this would be expected to increase the mean $E_{\mathrm{FRET}}$ of the $\mathrm{CE}$ vector. But as we have discussed, the measured value is actually lower than the corresponding duplex, not higher. Thus if the junction has the $3 \mathrm{HS}_{4}$ secondary structure, it must be strongly biased to the C-on-E stacking conformer.

By contrast, if the junction has either a $2 \mathrm{HS}_{1} \mathrm{HS}_{3}$ or $2 \mathrm{HS}_{2} \mathrm{HS}_{2}$ secondary structure the bias to the single C-on-E stacking conformer is immediately explained, because the e strand is the only one lacking a linker. The in-line probing experiment data point toward the $2 \mathrm{HS}_{1} \mathrm{HS}_{3}$ structure with the identification of a single flexible nucleotide on the $e x$ strand c, multiple flexible nucleotides on the en strand d, and absence of cleavage on the con strand e. However, this indirect method cannot be regarded as conclusive proof of the structure. If the predominant form is $2 \mathrm{HS}_{1} \mathrm{HS}_{3}$, then the structure adopted is quite unusual. It is a Len structure, in which the nonstacked $\mathrm{D}$ arm bends into the same quadrant as the $\mathrm{C}$ arm. In principle, the nonstacked might bend either way, so that the linker-containing strand turns through an angle that is greater or less than $90^{\circ}$. If we imagine fusing a fourth helix at the position of the linker, these would correspond to parallel or anti-parallel conformations of the resulting four-way junction, respectively. In Len junctions of known structure the linker generally turns through $>90^{\circ}$ (a pseudoparallel structure, where the ex and en strands cross one another), including the hammerhead ribozyme (Pley et al. 1994; Scott et al. 1995), the VS ribozyme III-IV-V junction (Lafontaine et al. 2002), as well as various cases identified in the ribosome by Lescoute and Westhof (2006). But in the $2 \mathrm{HS}_{1} \mathrm{HS}_{3}$ secondary structure, the shorter linker turns through $<90^{\circ}$, adopting the pseudo-anti-parallel structure. This seems to be without precedent in the structural database; no $2 \mathrm{HS}_{1} \mathrm{HS}_{3}$ three-way junction appears in the RNA junction database (Bindewald et al. 2008). On the other hand, if the junction has a $2 \mathrm{HS}_{2} \mathrm{HS}_{2}$ secondary structure the resulting junction is Leq. These tend to fall into the Westhof family B structure, which is pseudoparallel.

In summary, all the evidence indicates that the three-way junction adopts a rather stable fold, in a single stacking conformer, fixing the trajectory of helix IIId (helix D in this study) in the structure. It is possible that it undergoes some limited branch migration that is not detectable in our single-molecule experiments, but no exchange with an alternative stacking conformer has been detected. It is likely that this structurally stable junction has been selected by a requirement for this relatively small RNA to adopt a stable structure that can mediate the interactions with the $40 \mathrm{~S}$ ribosomal subunit and the translational initiation factor eIF3. While this structure may become distorted upon binding to the ribosome, its stability suggests that it will retain its conformation.

\section{MATERIALS AND METHODS}

\section{RNA synthesis and preparation of junctions}

RNA oligonucleotides were made by chemical synthesis, either commercially using 2'-ACE chemistry (Dharmacon) or using $t$-BDMS phosphoramidite chemistry (Beaucage and Caruthers 1981), as described by Wilson et al. (2001). Fluorescein and Cy3 fluorophores were coupled to the oligonucleotides used in the steady-state fluorescence measurements during synthesis. For single-molecule studies all oligonucleotides were made with $5^{\prime}$ aminolinkers, and $\mathrm{Cy} 3$ and $\mathrm{Cy} 5$ fluorophores were conjugated as $\mathrm{N}$-hydroxysuccinimide esters (Amersham Biosciences). All oligonucleotides were purified by gel electrophoresis in polyacrylamide, and recovered from gel fragments by electroelution or diffusion 
in buffer followed by ethanol precipitation. Fluorescently labeled RNA was subjected to further purification by reversed-phase HPLC on a C18 column (Waters $\mu$-Bondapak) using an acetonitrile gradient with an aqueous phase of $100 \mathrm{mM}$ triethylammonium acetate at $\mathrm{pH}$ 7.0.

Three-way junctions were constructed by mixing one Cy3labeled strand, one Cy5-labeled strand, and the remaining nonlabeled strand (each $300 \mathrm{pmol}$ ) in $90 \mathrm{mM}$ Tris-borate ( $\mathrm{pH} \mathrm{7.0)}$ and $25 \mathrm{mM} \mathrm{NaCl}$, and annealed by heating at $85^{\circ} \mathrm{C}$ and cooled slowly to $4^{\circ} \mathrm{C}$. The hybridized junctions were purified by electrophoresis in $20 \%$ polyacrylamide in $90 \mathrm{mM}$ Tris-borate $(\mathrm{pH} 8.3$ ) and $25 \mathrm{mM} \mathrm{NaCl}$, and recovered by electroelution and ethanol precipitation.

\section{Transcription of RNA}

DNA templates were prepared by 30 cycles of PCR using KOD Hot Start DNA polymerase (Novagen) and $1 \mu \mathrm{M}$ of each overlapping oligonucleotide, with an annealing temperature of $66^{\circ} \mathrm{C}$. RNA was transcribed from $0.15 \mu \mathrm{M}$ of PCR product in the presence of $40 \mathrm{mM}$ Tris- $\mathrm{HCl}(\mathrm{pH} 8.0), 20 \mathrm{mM} \mathrm{MgCl}_{2}, 2 \mathrm{mM}$ spermidine, $4 \mathrm{mM}$ of each NTP (Roche), $0.1 \mathrm{U}$ of pyrophosphatase (Sigma), $0.01 \%$ Triton X-100 (Sigma), and T7 RNA polymerase for $2.5 \mathrm{~h}$ at $37^{\circ} \mathrm{C}$ (Milligan et al. 1987). The RNA was purified by electrophoresis in a $6 \%$ polyacrylamide gel containing $7 \mathrm{M}$ urea. It was visualized by UV shadowing and recovered by electroelution into $8 \mathrm{M}$ ammonium acetate and ethanol precipitation. Purified RNA (6 pmol) was radioactively $5^{\prime}{ }_{-}^{32} \mathrm{P}$-labeled using T4 polynucleotide kinase (NEB) and $80 \mathrm{nM}$ of $\left[\gamma^{-32} \mathrm{P}\right]-\mathrm{ATP}$ $\left(6000 \mathrm{Ci} / \mathrm{mmol}\right.$; Perkin-Elmer) for $1 \mathrm{~h}$ at $37^{\circ} \mathrm{C}$.

\section{Comparative gel electrophoresis}

Radioactively $\left[5^{\prime}-{ }^{32} \mathrm{P}\right]$-labeled species were electrophoresed in $10 \%$ polyacrylamide gels (29:1, acrylamide:bis) in $90 \mathrm{mM}$ Tris-borate ( $\mathrm{pH} 8.3$ ), plus added salts or $2 \mathrm{mM}$ EDTA as required. Electrophoresis was performed at $120 \mathrm{~V}$ at room temperature, with recirculation of the buffer at $>1 \mathrm{~h} \mathrm{~h}^{-1}$. Gels were dried onto Whatman $3 \mathrm{MM}$ paper, exposed to storage phosphor plates, and imaged using a Fuji BAS-1500 PhosphorImager.

The sequences used for the electrophoretic experiments were:

c strand: 5'-GCGCAAGCGACAGGAACCUCGAGGGAUCCGGC GGACUGCUAGCCGAGUACGCGAAGCUUCUCGAGGUUC CUGUCGCUUGCGC-3';

d strand: 5'-GCGCAAGCGACAGGAACCUCGAGAAGCUUCGC GUACUCGGCCUUGUGGUCUCACGCGUCUAGACUCGAG GUUCCUGUCGCUUGCGC-3'; and

e strand: 5'-GCGCAAGCGACAGGAACCUCGAGUCUAGACGC GUGAGACCAUAGCAGUCCGCCGGAUCCCUCGAGGUUC CUGUCGCUUGCGC-3'.

Further shortened strands were made in order to truncate selected helical arms to $10 \mathrm{bp}$.

\section{Steady-state fluorescence spectroscopy}

Fluorescence spectra were recorded in $90 \mathrm{mM}$ Tris-borate $(\mathrm{pH}$ 8.3) at $4^{\circ} \mathrm{C}$ using an SLM-Aminco 8100 fluorimeter with Phoenix Electronics (ISS). Spectra were corrected for lamp fluctuations and instrumental variations, and polarization artifacts were avoided by setting excitation and emission polarizers crossed at $54.7^{\circ}$. Values of FRET efficiency $\left(E_{\mathrm{FRET}}\right)$ were measured using the acceptor normalization method (Clegg 1992) implemented in MATLAB. FRET efficiency as a function of metal ion concentration was analyzed on the basis of a model in which the fraction of folded molecules corresponds to a simple two-state model for ion-induced folding, i.e.,

$$
E_{\mathrm{FRET}}=E^{0}+\Delta E_{\mathrm{FRET}} K_{\mathrm{A}}[\mathrm{M}]^{n} /\left(1+K_{\mathrm{A}}[\mathrm{M}]^{n}\right),
$$

where $E^{0}$ is the FRET efficiency of the RNA in the absence of added metal ions, $\Delta E_{\mathrm{FRET}}$ is the increase in FRET efficiency at saturating metal ion concentration, $[\mathrm{M}]$ is the prevailing metal ion concentration, $K_{\mathrm{A}}$ is the apparent association constant for metal ion binding, and $n$ is a Hill coefficient. Data were fitted to this equation by nonlinear regression. The $\mathrm{Mg}^{2+}$ ion concentration at which the transition is half complete $\left(\left[\mathrm{Mg}^{2+}\right]_{1 / 2}\right)$ is given by $\left(1 / K_{\mathrm{A}}\right)^{1 / n}$.

The sequences used in the FRET analyses were:

c strand: 5'-CCUUGACUGCUAGCCGAGUACAGG-3'; d strand: $5^{\prime}$-CCUGUACUCGGCCUUGUGGUCUCAACGG- ${ }^{\prime}$; and e strand: $5^{\prime}$-CCGUUGAGACCAUAGCAGUCAAGG-3'.

A duplex corresponding to coaxially stacked C and E arms was made by hybridization of Cy5-labeled e strand to its complement (e' strand) 5'-labeled with Cy3:

$\mathrm{e}^{\prime}$ strand: 5'-CCUUGACUGCUAUGGUCUCAACGG-3'.

\section{Encapsulation of RNA junctions in phospholipid vesicles for single-molecule studies}

A 100:1 molar ratio of unmodified and biotinylated phospholipids was prepared by evaporating a number of aliquots of a mixture of $2.5 \mathrm{mg} \mathrm{L}-\alpha$-phosphatidylcholine and $35 \mu \mathrm{g}$ 1,2-dipalmitoyl$s n$-glycero-3-phosphoethanolamine-N-(cap biotinyl) (Avanti Polar Lipids, Inc.) from chloroform in a stream of argon. The aliquots were hydrated in $250 \mu \mathrm{L}$ of $50 \mathrm{mM} \mathrm{NaCl}, 10 \mathrm{mM}$ Tris$\mathrm{HCl}$ ( $\mathrm{pH}$ 8.1) (TN50 buffer) without (one aliquot, used for surface coating of slides) or with an addition of $200 \mathrm{nM}$ of a given fluorescent RNA junction and $10 \mathrm{mM} \mathrm{MgCl}_{2}$, corresponding to 5 pmol of RNA in a final volume of $250 \mu \mathrm{L}$.

The RNA was encapsulated in phospholipid vesicles by repeated extrusion through a polycarbonate membrane containing 200-nm pores using a mini-extruder (both Avanti Polar Lipids, Inc.), creating 200-nm diameter unilamellar vesicles (Boukobza et al. 2001; Okumus et al. 2004). The ratio of RNA to phospholipid resulted in most vesicles being empty, and thus most encapsulations involved a single RNA junction molecule. Slides were prepared by injection of RNA-free phospholipid vesicles into a narrow channel made between a quartz microscope slide and coverslip No 1.5 (VWR international) using double-sided adhesive tape, and left at $4^{\circ} \mathrm{C}$ for $1 \mathrm{~h}$ to allow supported bilayer formation. The sample chamber was then washed with TN50 buffer, treated with $0.2 \mathrm{mg} / \mathrm{mL}$ neutravidin (Pierce) for $10 \mathrm{~min}$, and washed. A 1/20th dilution of a chosen encapsulated RNA was injected and allowed to bind to the neutravidin for $15 \mathrm{~min}$. Imaging was performed under the same buffer conditions used for vesicle preparation with an oxygen-scavenging system consisting of $1.6 \mathrm{mg} / \mathrm{mL}$ of glucose oxidase, $0.2 \mathrm{mg} / \mathrm{mL}$ of catalase, $6 \%(\mathrm{w} / \mathrm{v})$ glucose, and 
$1 \mathrm{mM}$ TROLOX (6-hydroxy-2,5,7,8-tetramethylchroman-2-carboxylic acid).

\section{Total internal reflection single-molecule microscopy}

Fluorescence intensities at donor and acceptor wavelengths were acquired from single junction molecules encapsulated in phospholipid vesicles using total internal reflection fluorescence microscopy. The sample was mounted on the stage of an inverted microscope (Olympus IX70) and excited via the evanescent field generated by the total internal reflection of light from a solid state 532-nm laser (Crystalaser) via a quartz prism. Fluorescent emission was collected by a 1.2-numerical aperture $60 \mathrm{X}$ water immersion objective lens (Olympus), and separated by a $645-\mathrm{nm}$ dichroic mirror (Chroma Technology) into the donor and the acceptor fluorescence. These were focused side by side into a backilluminated EMCCD camera (iXON, Andor Technology) (Ha 2001). Hundreds of molecules could be recorded simultaneously using an image area of $8.2 \times 8.2 \mathrm{~mm}(512 \times 512$ active pixels $)$. Data were acquired using software written in Visual C++ (Microsoft), where each frame had a duration of $100 \mathrm{msec}$ (10 frames $\mathrm{sec}^{-1}$ ) for the population histograms and $8 \mathrm{msec}$ (125 frames $\mathrm{sec}^{-1}$ ) for the cross-correlation analysis. The highest acquisition rate of the camera is $33 \mathrm{msec}$, but faster rates can be attained by subdivision of the active number of pixels $(16 \mathrm{msec} /$ frame can be achieved dividing the chip by 2 and up to $8 \mathrm{msec} /$ frame using one quarter of the chip).

Measurements were performed at room temperature. Singlemolecule FRET efficiency after background correction was approximated by $E_{\mathrm{FRET}}=I_{\mathrm{A}} /\left(I_{\mathrm{A}}+I_{\mathrm{D}}\right)$, where $I_{\mathrm{A}}$ and $I_{\mathrm{D}}$ are the fluorescence intensities of the acceptor and donor, respectively. Because the quantum yields and detection efficiencies of Cy3 and Cy5 are very close, $E_{\mathrm{FRET}}$ closely matches the true efficiency of energy transfer. However, the spectral overlap separation of Cy3 and Cy5 is not total and the $645-\mathrm{nm}$ separation led to $\sim 10 \%$ of Cy3 leakage into the Cy5 channel. This introduces an apparent $E_{\text {FRET }}$ around 0.1 for a single active Cy3 fluorophore in the absence of the Cy5 acceptor.

Data analysis was carried out using laboratory-written analysis routines developed in MATLAB. Single-molecule FRET histograms were obtained using the whole FRET trace, while the population histograms were obtained by averaging frames 11-20 for every individual molecule after manually filtering photobleaching and blinking effects. Filtering involved removal of time traces in which (1) the fluorescence intensity of the acceptor was lower than 50-55 (caused by the absence of Cy5 fluorescence); (2) the total intensity was higher than 550-700 (indicating the presence of multiple fluorophores); (3) absence of anti-correlation between both fluorescence intensities during a blinking, dynamic, or a photobleaching event; (4) the total intensity was irregular over the length of the time-trace; and (5) multiple photobleaching events from the same fluorophore.

Cross-correlation analysis was performed using a program implemented in MATLAB. Records of donor and acceptor intensities as a function of time for single-junction molecules were analyzed using the following equation:

$$
G(\tau)=\frac{\sum\left[I_{\mathrm{D}}(t)-\overline{I_{\mathrm{D}}}\right] \cdot\left[I_{\mathrm{A}}(t+\tau)-\overline{I_{\mathrm{A}}}\right]}{N \cdot \sum \overline{I_{\mathrm{D}}} \cdot \overline{I_{\mathrm{A}}}}
$$

where $\overline{I_{\mathrm{D}}}$ and $\overline{I_{\mathrm{A}}}$ are mean donor and acceptor intensities, respectively, over the whole data record, normalized by the number of points summed $(N)$. The function $G(\tau)$ correlates the donor intensity at time $t$ with acceptor intensity at time increment $\tau$ later.

\section{In-line probing of nucleotide flexibility}

Two forms of the IRES junction were generated by transcription of a single RNA species, forming junctions with $5^{\prime}$-termini in either the $\mathrm{C}$ or $\mathrm{D}$ arms (Fig. 7):

\section{Terminus in C helix: 5'-GGGCAGUCAACUGAUGAGGCCGAAA GGCCGAAACGCGAAAGCGUCUUGACUGCUAGCCGAGU AGCUUUACUCGGCCUUGUGGUCUCAGCUUUGAGACCA UAGCAGUCAA-3'; and \\ Terminus in D helix: $5^{\prime}$-GGGCCGAGUACUGAUGAGGCCGAAA GGCCGAAACGCGAAAGCGUCUACUCGGCCUUGUGGUC UCAGCUUUGAGACCAUAGCAGUCAAGCUUUUGACUGC UAGCCGAGUA-3'.}

During transcription, the hammerhead ribozyme (underlined) underwent cleavage generating a homogenous 5 '-end at the IRES junction RNA. These were separately subjected to the in-line probing analysis of Soukup and Breaker (1999). Approximately 0.1 pmol of $\left[5^{\prime}{ }^{32} \mathrm{P}\right]$-labeled RNA was incubated in $20 \mu \mathrm{L} 50 \mathrm{mM}$ Tris$\mathrm{HCl}$ (pH 8.3), $100 \mathrm{mM} \mathrm{KCl}$, and $20 \mathrm{mM} \mathrm{MgCl}_{2}$ between $1 \mathrm{~min}$ and $48 \mathrm{~h}$ at $21^{\circ} \mathrm{C}$. Aliquots were diluted with $0.5 \mathrm{vol}$ of $100 \mathrm{mM}$ Tris- $\mathrm{HCl}(\mathrm{pH} 7.5)$ and $20 \mathrm{mM}$ EDTA in formamide (termination buffer). Uniformly cleaved RNA was generated by heating 0.1 pmol $\left[5^{\prime}-{ }^{32} \mathrm{P}\right]$-labeled RNA in $50 \mathrm{mM} \mathrm{NaOH}$ at $90^{\circ} \mathrm{C}$ for $20 \mathrm{sec}$ before addition of six volumes of termination buffer and placing on ice. RNA bands were assigned by comparison with $0.1 \mathrm{pmol}$ $\left[5^{\prime}{ }_{-}{ }^{32} \mathrm{P}\right]$-labeled RNA partial digested with $0.4 \mathrm{U}$ of ribonuclease T1 (which cleaves $3^{\prime}$ to $\mathrm{G}$ nucleotides) in the buffer provided by the manufacturer (Ambion). Products of cleavage were separated by electrophoresis in 10\% Long Ranger (Lonza) polyacrylamide gels containing $7 \mathrm{M}$ urea, $40 \%$ formamide, $90 \mathrm{mM}$ Tris-borate ( $\mathrm{pH} 8.3$ ), and $10 \mathrm{mM}$ EDTA, dried onto Whatman 3MM paper, and visualized by exposure to storage phosphor plates and phosphorimaging (Fuji).

\section{ACKNOWLEDGMENTS}

We thank Dr. Tim Wilson for discussions, Dr. Carlos Penedo for providing software, and Cancer Research UK for financial support of these studies.

Received March 3, 2010; accepted May 4, 2010.

\section{REFERENCES}

Ban N, Nissen P, Hansen J, Moore PB, Steitz TA. 2000. The complete atomic structure of the large ribosomal subunit at $2.4 \AA$ resolution. Science 289: 905-920.

Beaucage SL, Caruthers MH. 1981. Deoxynucleoside phosphoramiditesa new class of key intermediates for deoxypolynucleotide synthesis. Tetrahedron Lett 22: 1859-1862.

Bindewald E, Hayes R, Yingling YG, Kasprzak W, Shapiro BA. 2008. RNAJunction: A database of RNA junctions and kissing loops for three-dimensional structural analysis and nanodesign. Nucleic Acids Res 36: D392-D397. 
Boehringer D, Thermann R, Ostareck-Lederer A, Lewis JD, Stark H. 2005. Structure of the hepatitis $C$ virus IRES bound to the human $80 S$ ribosome: Remodeling of the HCV IRES. Structure 13: 1695-1706.

Boukobza E, Sonnenfeld A, Haran G. 2001. Immobilization in surface-tethered lipid vesicles as a new tool for single biomolecule spectroscopy. J Phys Chem B 105: 12165-12170.

Brown EA, Zhang H, Ping LH, Lemon SM. 1992. Secondary structure of the $5^{\prime}$ nontranslated regions of hepatitis $\mathrm{C}$ virus and pestivirus genomic RNAs. Nucleic Acids Res 20: 5041-5045.

Clegg RM. 1992. Fluorescence resonance energy transfer and nucleic acids. Methods Enzymol 211: 353-388.

de la Pena M, Dufour D, Gallego J. 2009. Three-way RNA junctions with remote tertiary contacts: A recurrent and highly versatile fold. RNA 15: 1949-1964.

Duckett DR, Murchie AIH, Diekmann S, von Kitzing E, Kemper B, Lilley DMJ. 1988. The structure of the Holliday junction and its resolution. Cell 55: 79-89.

Duckett DR, Murchie AIH, Lilley DMJ. 1995. The global folding of four-way helical junctions in RNA, including that in U1 snRNA. Cell 83: 1027-1036.

Förster T. 1948. Zwischenmolekulare energiewanderung und fluoreszenz. Ann Phys 2: 55-75.

Garst AD, Heroux A, Rambo RP, Batey RT. 2008. Crystal structure of the lysine riboswitch regulatory mRNA element. J Biol Chem 283: 22347-22351.

Ha T. 2001. Single-molecule fluorescence resonance energy transfer. Methods 25: 78-86.

Honda M, Ping LH, Rijnbrand RC, Amphlett E, Clarke B, Rowlands D, Lemon SM. 1996. Structural requirements for initiation of translation by internal ribosome entry within genome-length hepatitis C virus RNA. Virology 222: 31-42.

Honda M, Beard MR, Ping LH, Lemon SM. 1999. A phylogenetically conserved stem-loop structure at the $5^{\prime}$ border of the internal ribosome entry site of hepatitis $\mathrm{C}$ virus is required for capindependent viral translation. J Virol 73: 1165-1174.

Iqbal A, Arslan S, Okumus B, Wilson TJ, Giraud G, Norman DG, Ha T, Lilley DMJ. 2008a. Orientation dependence in fluorescent energy transfer between Cy3 and Cy5 terminally attached to doublestranded nucleic acids. Proc Natl Acad Sci 105: 11176-11181.

Iqbal A, Wang L, Thompson KC, Lilley DMJ, Norman DG. 2008b. The structure of cyanine 5 terminally attached to doublestranded DNA: Implications for FRET studies. Biochemistry 47: $7857-7862$.

Jubin R, Vantuno NE, Kieft JS, Murray MG, Doudna JA, Lau JY, Baroudy BM. 2000. Hepatitis C virus internal ribosome entry site (IRES) stem-loop IIId contains a phylogenetically conserved GGG triplet essential for translation and IRES folding. J Virol 74: 1043010437.

Kieft JS, Zhou K, Jubin R, Murray MG, Lau JY, Doudna JA. 1999. The hepatitis $\mathrm{C}$ virus internal ribosome entry site adopts an iondependent tertiary fold. J Mol Biol 292: 513-529.

Kieft JS, Zhou K, Jubin R, Doudna JA. 2001. Mechanism of ribosome recruitment by hepatitis C IRES RNA. RNA 7: 194-206.

Kieft JS, Zhou K, Grech A, Jubin R, Doudna JA. 2002. Crystal structure of an RNA tertiary domain essential to HCV IRESmediated translation initiation. Nat Struct Biol 9: 370-374.

Klinck R, Westhof E, Walker S, Afshar M, Collier A, Aboul-ela F. 2000. A potential RNA drug target in the hepatitis $C$ virus internal ribosomal entry site. RNA 6: 1423-1431.

Kolupaeva VG, Pestova TV, Hellen CU. 2000. An enzymatic footprinting analysis of the interaction of $40 \mathrm{~S}$ ribosomal subunits with the internal ribosomal entry site of hepatitis C virus. J Virol 74: 6242-6250.

Lafontaine DA, Norman DG, Lilley DMJ. 2002. The global structure of the VS ribozyme. EMBO J 21: 2461-2471.

Lescoute A, Westhof E. 2006. Topology of three-way junctions in folded RNAs. RNA 12: 83-93.

Lilley DMJ. 2000. Structures of helical junctions in nucleic acids. Q Rev Biophys 33: 109-159.
Lilley DMJ. 2008. Analysis of branched nucleic acid structure using comparative gel electrophoresis. Q Rev Biophys 41: 1-39.

Lilley DMJ. 2009a. Comparative gel electrophoresis analysis of helical junctions in RNA. Methods Enzymol 469: 143-177.

Lilley DMJ. 2009b. The structure and folding of branched RNA analyzed by fluorescence resonance energy transfer. Methods Enzymol 469: 159-187.

Lilley DMJ, Clegg RM, Diekmann S, Seeman NC, von Kitzing E, Hagerman P. 1995. Nomenclature Committee of the International Union of Biochemistry: A nomenclature of junctions and branchpoints in nucleic acids. Recommendations 1994. Eur J Biochem 230: $1-2$.

Lipfert J, Ouellet J, Norman DG, Doniach S, Lilley DMJ. 2008. The complete VS ribozyme in solution studied by small-angle X-ray scattering. Structure 16: 1357-1367.

Lukavsky PJ, Otto GA, Lancaster AM, Sarnow P, Puglisi JD. 2000. Structures of two RNA domains essential for hepatitis C virus internal ribosome entry site function. Nat Struct Biol 7: 11051110.

Lukavsky PJ, Kim I, Otto GA, Puglisi JD. 2003. Structure of HCV IRES domain II determined by NMR. Nat Struct Biol 10: 10331038.

Martick M, Horan LH, Noller HF, Scott WG. 2008. A discontinuous hammerhead ribozyme embedded in a mammalian messenger RNA. Nature 454: 899-902.

Melcher SE, Wilson TJ, Lilley DMJ. 2003. The dynamic nature of the four-way junction of the hepatitis C virus IRES. RNA 9: 809820 .

Milligan JF, Groebe DR, Witherall GW, Uhlenbeck OC. 1987. Oligoribonucleotide synthesis using T7 RNA polymerase and synthetic DNA templates. Nucleic Acids Res 15: 8783-8798.

Murchie AIH, Thomson JB, Walter F, Lilley DMJ. 1998. Folding of the hairpin ribozyme in its natural conformation achieves close physical proximity of the loops. Mol Cell 1: 873-881.

Norman DG, Grainger RJ, Uhrin D, Lilley DMJ. 2000. The location of Cyanine-3 on double-stranded DNA; importance for fluorescence resonance energy transfer studies. Biochemistry 39: 6317-6324.

Okumus B, Wilson TJ, Lilley DMJ, Ha T. 2004. Vesicle encapsulation studies reveal that single molecule ribozyme heterogeneities are intrinsic. Biophys J 87: 2798-2806.

Orr JW, Hagerman PJ, Williamson JR. 1998. Protein and $\mathrm{Mg}^{2+}-$ induced conformational changes in the S15 binding site of $16 \mathrm{~S}$ ribosomal RNA. J Mol Biol 275: 453-464.

Pley HW, Flaherty KM, McKay DB. 1994. Three-dimensional structure of a hammerhead ribozyme. Nature 372: 68-74.

Reynolds JE, Kaminski A, Kettinen HJ, Grace K, Clarke BE, Carroll AR, Rowlands DJ, Jackson RJ. 1995. Unique features of internal initiation of hepatitis C virus RNA translation. EMBO J 14: 60106020.

Rijnbrand R, Bredenbeek P, van der Straaten T, Whetter L, Inchauspe G, Lemon S, Spaan W. 1995. Almost the entire 5' nontranslated region of hepatitis $\mathrm{C}$ virus is required for cap-independent translation. FEBS Lett 365: 115-119.

Scott WG, Finch JT, Klug A. 1995. The crystal structure of an all-RNA hammerhead ribozyme: A proposed mechanism for RNA catalytic cleavage. Cell 81: 991-1002.

Serganov A, Yuan YR, Pikovskaya O, Polonskaia A, Malinina L, Phan AT, Hobartner C, Micura R, Breaker RR, Patel DJ. 2004. Structural basis for discriminative regulation of gene expression by adenineand guanine-sensing mRNAs. Chem Biol 11: 1729-1741.

Serganov A, Huang L, Patel DJ. 2008. Structural insights into amino acid binding and gene control by a lysine riboswitch. Nature 455: 1263-1267.

Sizova DV, Kolupaeva VG, Pestova TV, Shatsky IN, Hellen CU. 1998. Specific interaction of eukaryotic translation initiation factor 3 with the $5^{\prime}$ nontranslated regions of hepatitis $\mathrm{C}$ virus and classical swine fever virus RNAs. J Virol 72: 4775-4782.

Soukup GA, Breaker RR. 1999. Relationship between internucleotide linkage geometry and the stability of RNA. RNA 5: 1308-1325. 
Spahn CM, Kieft JS, Grassucci RA, Penczek PA, Zhou K, Doudna JA, Frank J. 2001. Hepatitis C virus IRES RNA-induced changes in the conformation of the 40S ribosomal subunit. Science 291: 1959-1962.

Tsukiyama-Kohara K, Iizuka N, Kohara M, Nomoto A. 1992. Internal ribosome entry site within hepatitis C virus RNA. J Virol 66: 14761483.

Walter F, Murchie AIH, Thomson JB, Lilley DMJ. 1998. Structure and activity of the hairpin ribozyme in its natural junction conformation; effect of metal ions. Biochemistry 37: 14195-14203.
Wang C, Sarnow P, Siddiqui A. 1993. Translation of human hepatitis $\mathrm{C}$ virus RNA in cultured cells is mediated by an internal ribosomebinding mechanism. J Virol 67: 3338-3344.

Wilson TJ, Zhao Z-Y, Maxwell K, Kontogiannis L, Lilley DMJ. 2001. Importance of specific nucleotides in the folding of the natural form of the hairpin ribozyme. Biochemistry 40: 2291-2302.

Wimberly BT, Brodersen DE, Clemons WM Jr, Morgan-Warren RJ, Carter AP, Vonrhein C, Hartsch T, Ramakrishnan V. 2000. Structure of the 30 S ribosomal subunit. Nature 407: 327-339. 

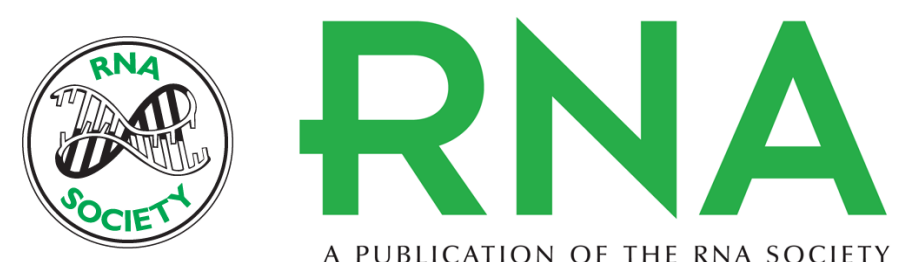

A PUBLICATION OF THE RNA SOCIETY

\section{Structure of the three-way helical junction of the hepatitis C virus IRES element}

Jonathan Ouellet, Sonya Melcher, Asif Iqbal, et al.

RNA 2010 16: 1597-1609 originally published online June 25, 2010

Access the most recent version at doi:10.1261/rna.2158410

$\begin{array}{ll}\text { References } & \begin{array}{l}\text { This article cites } 54 \text { articles, } 16 \text { of which can be accessed free at: } \\ \text { http://rnajournal.cshlp.org/content/16/8/1597.full.html\#ref-list-1 }\end{array}\end{array}$

License

Email Alerting Receive free email alerts when new articles cite this article - sign up in the box at the Service top right corner of the article or click here. 